\title{
Preface
}

\section{Paul Heitjans* Mobility of Ions in Solids}

DOI 10.1515/zpch-2017-5000

The mobility and diffusivity of ions in solids is a vital topic for fundamental as well as application-inspired research. The present Themed Issue of Zeitschrift für Physikalische Chemie contains a number of contributions to a Bunsen Colloquium entitled Mobility of Ions in Solids, which took place at Leibniz Universität Hannover (Hannover, Germany) on 5-6 April 2017 under the auspices of the Deutsche Bunsengesellschaft für Physikalische Chemie. This Colloquium followed previous Bunsen Colloquia on related topics held in Hannover in 2014, 2011 and 2009 whose contributions appeared in part also as special issues of Zeitschrift für Physikalische Chemie [1-3].

The Bunsen Colloquium 2017 was conceived, on the one hand, as the final colloquium of the Research Unit FOR 1277 Mobilität von Lithiumionen in Festkörpern (molife) of the Deutsche Forschungsgemeinschaft (DFG). Molife has been devoted to the fundamentals of Li diffusion and transport - fast as well as slow - in crystalline and amorphous ceramics, being studied by a large variety of experimental and theoretical methods. See Figure 1 for an overview of the leitmotifs of the molife "house" with the four "storeys" Phenomena, Materials, Methods, Models.

Molife has been running since 2010 with Leibniz Universität Hannover as Speaker University and further groups from Technische Universität Berlin, Universität Bonn, Technische Universität Clausthal, Technische Universität Graz and Universität Oldenburg. It has comprised seven research subprojects entitled (i) Low-dimensional lithium ion conductors, (ii) Diffusion pathways and activation energies in crystalline lithium ion conductors, (iii) Isotopic effects, jump correlation and diffusion paths in Li-containing oxide glasses, (iv) Effect of pressure on transport properties of granular lithium ion conductors, (v) Kinetics of Li intercalation and de-intercalation in chalcogenide single crystals, (vi) Li Diffusion in oxide nanotubes as well as mesostructured layered materials and (vii) Ultraslow Li transport on the nanometer scale.

The 12 articles [4-15] collected in this issue are closely related to the above topics and mostly serve as final reports of the subprojects either in the form of

*Corresponding author: Paul Heitjans, Leibniz Universität Hannover, Hannover, e-mail: heitjans@pci.uni-hannover.de 


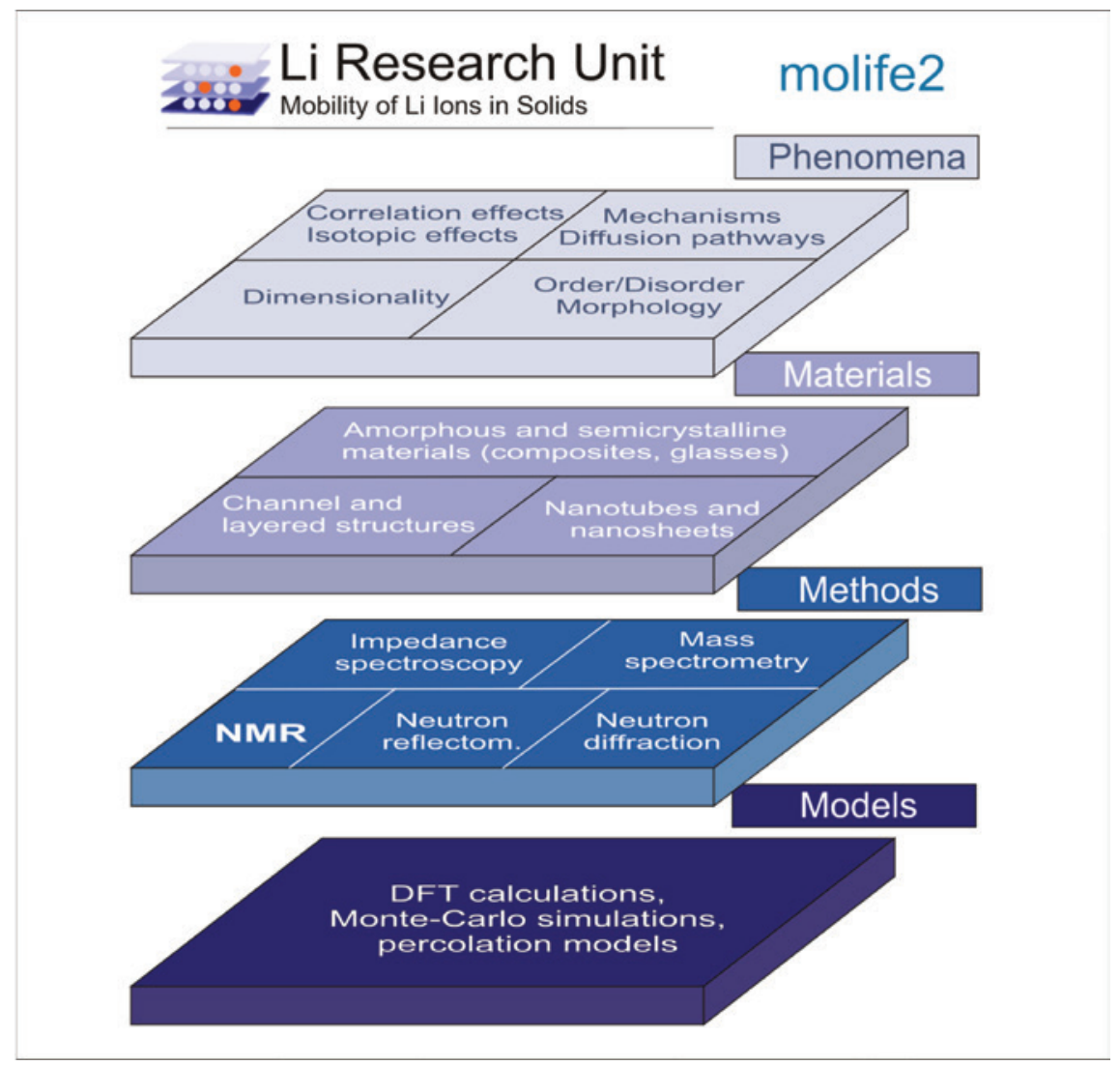

Fig. 1: Leitmotifs of the DFG Research Unit 1277 Mobility of Li lons in Solids (molife).

reviews or as accompanying original publications. For a current list of molife publications over the years and other information from molife see www.for1277molife. uni-hannover.de.

The Bunsen Colloquium 2017 was on the other hand - beyond molife intended to broaden the scope from lithium ion diffusion to the dynamics of other ions. In fact, besides motions of $\mathrm{Li}^{+}$, to a minor part those of $\mathrm{Na}^{+}, \mathrm{K}^{+}, \mathrm{Ca}^{2+}, \mathrm{F}^{-}$or $\mathrm{O}^{2-}$ were treated in the more than 30 contributions. Their extended abstracts are accessible in the Online Journal Diffusion Fundamentals, www.diffusion-fundamentals.org, Vol. 28 (2017). Among the articles in the present Themed Issue, references $[4,5,11]$ also include studies of the diffusion of sodium ions in addition to that of lithium ions. While the interest here is still mainly fundamental, such as for $\mathrm{Li}$, studies of "post Li" ion conductors often eventually aim at applications, in 
particular electrochemical energy storage devices or sensors. However, concerning this, there is still a long way to go.

I am very grateful to the authors from molife and friendly groups beyond for their contributions. For taking numerous tasks in the local organization of the Bunsen Colloquium, I cordially thank Harald Behrens, Sebastian Busch, Ngoc Anh-Thu Duong, Christopher Krich, David Murawski, Victoria Nebieridze, Kai Volgmann and Vanessa Werth. I also sincerely thank the reviewers of the manuscripts for their precious time and valuable comments. Special thanks are due to the members of the editorial staff of Zeitschrift für Physikalische Chemie who helped to prepare this issue. Support of the Colloquium was received from the Deutsche Bunsengesellschaft für Physikalische Chemie, Leibniz Zentrum für Festkörperchemie und Neue Materialien (ZFM), Bruker BioSpin GmbH and, in total, from the DFG in the frame of FOR 1277. On behalf of the members of FOR 1277, I also like to thank the referees and referents of the DFG for their work.

\section{References}

1. P. Heitjans (Ed.), Z. Phys. Chem. 229 (2015) 1263.

2. M. Wilkening (Ed.), Z. Phys. Chem. 226 (2012) 337.

3. P. Heitjans, M. Martin, M. Wilkening (Eds.), Diffusion Fundam. 12 (2010) 1.

4. K. Volgmann, V. Epp, J. Langer, B. Stanje, J. Heine, S. Nakhal, M. Lerch, M. Wilkening, P. Heitjans, Z. Phys. Chem. 231 (2017) 1215.

5. K. Volgmann, V. Werth, S. Nakhal, M. Lerch, T. Bredow, P. Heitjans, Z. Phys. Chem. 231 (2017) 1243.

6. V. Werth, K. Volgmann, M. M. Islam, P. Heitjans, T. Bredow, Z. Phys. Chem. 231 (2017) 1263.

7. D. Wiedemann, M. M. Islam, T. Bredow, M. Lerch, Z. Phys. Chem. 231 (2017) 1279.

8. A.-M. Welsch, H. Behrens, D. Murawski, I. Horn, Z. Phys. Chem. 231 (2017) 1303.

9. D. Murawski, H. Behrens, Z. Phys. Chem. 231 (2017) 1323.

10. N. I. Schwarzburger, H. Behrens, I. Horn, M. Binnewies, Z. Phys. Chem. 231 (2017) 1345.

11. D. Prutsch, S. Breuer, M. Uitz, P. Bottke, J. Langer, S. Lunghammer, M. Philipp, P. Posch, V. Pregartner, B. Stanje, A. Dunst, D. Wohlmuth, H. Brandstätter, W. Schmidt, V. Epp,

A. Chadwick, I. Hanzu, M. Wilkening, Z. Phys. Chem. 231 (2017) 1361.

12. O. Wittich, F. Meyer, M. Wark, Z. Phys. Chem. 231 (2017) 1407.

13. J. Uhlendorf, B. Ruprecht, E. Witt, C. V. Chandran, L. Dörrer, E. Hüger, F. Strauß, P. Heitjans, H. Schmidt, Z. Phys. Chem. 231 (2017) 1423.

14. C. V. Chandran, K. Volgmann, S. Nakhal, R. Uecker, E. Witt, M. Lerch, P. Heitjans, Z. Phys. Chem. 231 (2017) 1443.

15. A. V. Skripov, K. Volgmann, C. V. Chandran, R. V. Skoryunov, O. A. Babanova, A. V. Soloninin, S. Orimo, P. Heitjans, Z. Phys. Chem. 231 (2017) 1455. 